\title{
Pt Heating Electrode for Microheater Based on Electrochemically Prepared Anodic Porous Alumina
}

\author{
Seungho Park ${ }^{1,2}$, Dongeun Lee ${ }^{1}$,Sunghyun Byun ${ }^{1}$, Hyeonseok Yoo ${ }^{3}$, Dong-Wha Park ${ }^{3}$, Woonsuk \\ Hwang $^{2, *}$, Jinsub Choi ${ }^{3, *}$ \\ ${ }^{1}$ Point Engineering, 89 Asan Valley-ro, Dunpo-myeon, Asan-si, Chungnam, South Korea \\ ${ }^{2}$ Department of Metallurgical Engineering, Inha University, Yonghyun Dong 253, 402-751, South \\ Korea \\ ${ }^{3}$ Department of Chemistry and Chemical Engineering, Center for Molecular Catalysts and \\ Applications (BK21 plus program), Inha University, Yonghyun Dong 253, 402-751, South Korea \\ *E-mail: wnshwang@inha.ac.kr, jinsub@inha.ac.kr
}

doi: $10.20964 / 2016.09 .43$

Received: 15 June 2016 / Accepted: 9 July 2016 / Published: 7 August 2016

\begin{abstract}
Electrochemically prepared anodic aluminum oxide (AAO) was used as a supporting chip material for a microheater sensor, on which a patterned Pt electrode was deposited to generate resistive heat during current flow. Photolithography and a Pt/Ta sputtering process were conducted to prepare an interdigited electrode on the AAO supporting material. For efficient heat management within the heating zone, an air-gap ring was created around the heating zone using a chemical etching process. A thermal infrared camera image revealed that the generated heat is isolated within the heating zone. To achieve stable heating performance of the Pt layer, the Pt deposited on AAO was thermally annealed under various conditions. With increasing annealing temperature, the grain size of the Pt planes increased, leading to a highly stable Pt electrode on AAO. However, increasing the annealing temperature to $650^{\circ} \mathrm{C}$ resulted in the generation of pinholes, which led to degraded heating properties. A very small amount of heating power $(50 \mathrm{~mW})$ was consumed to maintain a heating zone temperature of over $600^{\circ} \mathrm{C}$ in the proposed AAO-based microheater.
\end{abstract}

Keywords: anodization, nanopores, microheater, Pt sputtering, supporting chip materials

\section{$\underline{\text { FULL TEXT }}$}

(C) 2016 The Authors. Published by ESG (www.electrochemsci.org). This article is an open access article distributed under the terms and conditions of the Creative Commons Attribution license (http://creativecommons.org/licenses/by/4.0/). 